\title{
Berlusconi y el deporte como estrategia de comunicación política
}

\author{
Andrea DONOFRIO \\ Fundación Ortega y Gasset \\ adonofrio@hotmail.com
}

Recibido: 25 de marzo de 2012.

Aceptado: 1 de septiembre de 2012.

\section{Resumen}

El deporte y el fútbol resultaron fundamentales dentro de la estrategia política que permitió a Silvio Berlusconi acceder a la Presidencia del Gobierno italiano. El fútbol con su poder mediático se convirtió en una plataforma útil por sus finalidades electorales. La compra de un popular e histórico equipo supuso una buena intuición (hoy copiada por muchos jeques árabes), una manera para obtener prestigio y darse a conocer al país entero, operación conducida con la colaboración de los canales de televisión pertenecientes al magnate. Asimismo, creció el protagonismo del deporte, asistiendo a una constante "futbolarización" de la política y de la comunicación en general.

Palabras clave: Berlusconi; Italia; Milán; Fútbol; Medios de Comunicación

\section{Berlusconi and the sport as a political communication strategy}

\begin{abstract}
Sport and football were instrumental in the political strategy that allowed Silvio Berlusconi to access the Presidency of the Italian Government. Football with his media power became a useful platform for his electoral purposes. The acquisition of a popular and historic team represented a good intuition (now copied by many Arab sheikhs), a way to gain prestige and become known to the whole country, operation conducted with the cooperation of television channels of tycoon's property. As well, the prominence of the sport increased, attending a constant "futbolarizatión" of politics and communication in general.
\end{abstract}

Key words: Berlusconi; Italy; Milan; Football; Media.

\section{Referencia normalizada}

Donofrio, A. (2012). Berlusconi y el deporte como estrategia de comunicación política. Historia y Comunicación Social, Vol. 17, páginas 103-123.

Sumario: 1. Introducción. 2. La compra del Milán y la discesa in campo. 3. La subida al poder de Berlusconi. 4. La transformación de la política y del lenguaje. 5. El fenómeno Berlusconi. 6. Conclusiones. 7. Bibliografía. 


\section{Introducción}

La entrada de Silvio Berlusconi en la arena política italiana ha representado uno de los eventos fundamentales de los últimos años, uno de los acontecimientos que, probablemente, más consecuencias ha tenido en el desarrollo socio-económico y político del país. La decisión del magnate de gobernar Italia ha comportando, al mismo tiempo, la personalización y la espectacularización de la vida política nacional, junto con el declive de los tradicionales partidos políticos italianos. En estos años y tras varias contiendas electorales $(1994,2001,2006,2008)$, se ha asistido a un nuevo protagonismo de los medios de comunicación, al poder de la imagen, a la política como espectáculo, a la irrupción del video-poder, a una nueva concepción del deporte $-\mathrm{y}$ del fútbol especialmente- como parte integrante de una estrategia electoral y política. A lo largo de estas décadas, la acción política de Berlusconi se ha caracterizado por una elevada dosis de populismo, de matiz conservadora y derechista, aunque con algún importante elemento novedoso: el ex presidente del Gobierno inauguró un populismo basado en un estilo personal más que político, en el propio carisma, en la propia imagen, en el uso de los medios de comunicación y en la concepción de que el deporte representa un medio para movilizar votos. La presidencia del A.C. Milán, su populismo mediático y su influencia sobre los medios de comunicación han favorecido sus victorias electorales.

El objetivo de este artículo es reflexionar sobre el uso político del deporte por parte del ex presidente del Gobierno italiano, siendo consciente de que el fútbol representaba un medio, parte de una estrategia para obtener consenso y conseguir votos. Asimismo, como veremos, se asistió a una "futbolarización" del lenguaje político, a un abuso dialéctico de expresiones prevalentemente deportivas.

La metodología que seguiré a lo largo de este trabajo se centrará en un breve análisis de algún discurso político del ex presidente del Gobierno, artículos de prensa sobre el tema, noticias publicadas en periódicos tradicionales y digitales. Igualmente, se considera oportuno hacer referencia a la abundante literatura sobre el fenómeno Berlusconi, publicada especialmente en Italia y concerniente el tema objeto de reflexión.

\section{La compra del Milán y la discesa in campo}

En noviembre de 2011, Berlusconi dimitió una vez constatada la pérdida de la mayoría en el Parlamento italiano. No se ha tratado del fin de un gobierno normal, sino más bien de la conclusión de un largo régimen. La votación, para aprobar los presupuestos del 2010, selló el final de un ciclo, rubricando el ocaso del berlusconismo, mostrando los peligros de construir el propio poder sobre una base de clientelismo, populismo mediático y fidelidades personales. Tras casi dos décadas de poder, llegó el día de escribir la necrológica política de Berlusconi, el hombre que entró en política prometiendo menos impuestos y un nuevo milagro económico italiano, un país "vincente come il Milan", su equipo de fútbol y trampolín hacia su 
victoria electoral. Como afirmó el propio Berlusconi en 2006, "il calcio è metafora di vita: dai successi del Milan la gente ha capito che la mia è una filosofia vincente, che lavorando si possono raggiungere risultati ambiziosi"1.

Lamentablemente, la realidad ha sido muy diferente: Berlusconi abandona la escena dejando un país más pobre de cómo lo encontró, atrapado en una grave crisis económica e institucional. Su renuncia ha provocado una sensación de "fin de época", ya que su mandato se ha caracterizado por una invasión en la vida de los ciudadanos, estableciendo un control político, económico y mediático. Resulta de gran interés investigar cómo un empresario, dueño de un equipo de fútbol, de una ingente fortuna económica y de varios medios de comunicación puede convertirse en un Presidente democráticamente electo. Por eso, merece la pena investigar la estrategia política que utilizó, comprender las tácticas que emprendió, las técnicas que sirvieron para que el cavaliere consiguiera el poder y permaneciera agarrado al mismo durante dos décadas. El deporte, el fútbol y su retórica resultan fundamentales dentro de esta estrategia, ya que Silvio Berlusconi ha llegado a comprender que para los italianos el fútbol representa algo más que un juego: forma parte de su mundo, está tan arraigado en la sociedad que, para algunos, pasa de ser una pasión a representar una verdadera ideología o, incluso, un culto. Berlusconi entendió que podía representar un instrumento para alcanzar el poder y se sirvió de ello. Pasados unos años, resulta evidente que sus vinculaciones futbolísticas influyeron en su carrera política y, desde la compra del Milán (febrero 1986), uno de los clubes más ilustres del país, Berlusconi utilizó su cargo, la presidencia de un equipo, más allá de finalidades deportivas. La compra de un popular e histórico equipo de fútbol representó una buena intuición (que hoy parece copiada por muchos jeques árabes), una manera para obtener prestigio ciudadano y darse a conocer al país entero: el club alimentó su popularidad y acrecentó su fama, labor desenvuelta en colaboración con los propios canales de televisión pertenecientes al magnate.

Podemos incluso aventurarnos en un paralelo, una comparativa entre la adquisición del Milán en 1986 y la entrada en el escenario político italiano en 1994. Berlusconi compró el equipo de fútbol después de que este viviera una de sus épocas peores, una etapa convulsa que culminó con la implicación del conjunto rossonero en el célebre caso del totonero. Se investigaban una serie de partidos "amañados", para favorecer las quinielas negras o clandestinas ${ }^{2}$. Como resultado de la investigación, el Milán fue descendido administrativamente a Segunda (Serie B) por su participación en la trama. En este contexto, Berlusconi adquirió la propiedad del equipo, prometiendo que pronto le devolviera a la grandeza de antaño. Recordando que el equipo había sido Campeón de Europa en dos ocasiones y ganado 10 Ligas, el cavaliere remembraba antiguos esplendores y prometía, con su dinero siendo ya "el rey de la televisión privada", fichajes y éxitos. Y mantuvo su promesa: el éxito fue inmediato y el Milán volvió a ser un equipo ganador, respectado y temido en Italia y en el Mundo. Berlusconi se convertía en el Gran Presidente y en Milán le admiraban, considerándole un modelo de éxito, el hombre capaz de hacer todo, un self-made man. Con sus modales audaces y pretenciosos, prometía: "en mis actividades económicas suelo ser el número 1 , y estoy tan acostumbrado a ello que si 
acabara como número 2 en el fútbol me lo tomaría muy mal".

Con los mismos objetivos y promesas, Berlusconi decidió entrar en política tras la caída de la I República, derrumbada en un escándalo de corrupción y crisis. Tras el escándalo de Tangentopoli (Manos limpias), Berlusconi decidió aparecer en el escenario político como una posible solución, dispuesto a salvar al país, un mesías ${ }^{3}$ que, impulsado por el marketing publicitario, consiguió seducir a los italianos, prometiendo "cose buone" e improvisando a "golpes de genio". Se presentaba a sí mismo como una reencarnación del Rey Midas y que podía reanimar Italia y devolverle la grandeza de su pasado tal y como lo había logrado con el Milán. En todo momento, recordaba que era un magnate de la televisión, dueño de un equipo ganador, propietarios de muchas empresas. Ante la profunda crisis de los partidos tradicionales (la Democracia Cristiana y el Partido Comunista) y de su ideología, el cavaliere utilizó en su favor el hartazgo de los italianos hacia los políticos para inventarse un partido, carente de ideología y llamado Forza Italia, a certificar el ingreso oficial del deporte en la política. Como sabiamente afirmaba el periodista Miguel Ángel Basteneir, Berlusconi era "el gran empresario de su propio espectáculo, un circo político con grandes dosis de deporte (el Calcio), y con ello resultaba mucho más italiano, más auténtico que la tropa a la que reemplazaba"4. Así, en virtud de su actitud triunfadora, de una campaña mediática bien orquestada y centrada en su persona, presentado como el homo novus de Italia, el presidente del Milán Futbol Club pudo alcanzar el poder, dando vida a la insólita situación de un gran patrono de medios de comunicación que logra controlar el poder político directamente, provocando una peligrosa confusión entre intereses públicos y privados, personales y gubernamentales. El 27 de abril de 1994 es elegido Presidente del Gobierno italiano. El paralelismo con el Milán termina aquí ya que el resultado no fue el mismo: la gestión política del país resultó tan desastrosa en aquellos pocos meses (cayó en enero de 1995) como en los siguientes mandatos.

Podemos hallar un paralelismo más entre estas dos experiencias, aunque más que de una situación parecida se trata de un mínimo común denominador de la acción de Berlusconi: su presentación como presidente del equipo de fútbol se celebró en el estadio del Milán, repleto de seguidores expectantes, aterrizando en helicóptero, mientras sonaba la marcha de Las valquirias de Wagner. Descendió en el césped acompañado de unas vedettes guapas y lascivas, presencia que le acompañó también a lo largo de sus mandatos políticos. Su discurso, como el día de nombramiento como Presidente del Gobierno, era prometedor y triunfalista, dando, además muestra de su innata habilidad para conectar con los interlocutores. Aquel día y el día en que firmó en televisión el contrato con los italianos (en mayo 2001, copiando el "Contrato con América" del republicano Newt Gingrich), revelaban su capacidad para captar la atención de la gente. Esta virtud se confirmó a lo largo de su experiencia política, tanto que el periodista italiano del Corriere della Sera, Beppe Severginini, hablaba de un efecto Zelig: "sabe interpretar todos los papeles: familiar con las familias, mujeriego entre amigotes, joven entre jóvenes, empresario entre empresarios, norteño entre norteños, sureño entre sureños. Tiene en cada momento una ocurrencia, una broma, para caer simpático y ganarse al personal". 
Berlusconi supo comprender que el Ancien Régime se había derrumbado, dejando a más de la mitad de los italianos sin partido político. Por eso, se propuso llenar este vacío político, creando una partido, carente de ideología y con una marcada tendencia al populismo. Silvio supo entender que los ciudadanos estaban más interesados en el deporte que en la política, que sentían más propensión al entretenimiento que preocupación por la economía. Entendió que deporte y televisión podían representar una formidable pareja para publicitar su éxito económico, para anestesiar la opinión pública y convencer sus electores, entreteniéndoles, diciéndoles lo que querían escuchar, omitiendo lo malo e insistiendo sobre lo dudoso, poniendo cíclicamente en marcha la "máquina del fango" (paradigmas de las "amenazas" berlusconianas de "todos tienen esqueletos en el armario" y del "todos culpables, todos inocentes") para desprestigiar a sus adversarios y distraer la atención de su evidente conflicto de intereses. Creó de la nada un partido político sin una clara ideología, pero con un nombre pegadizo y fácilmente recordable: Forza Italia!, cántico popular de las selecciones italianas de fútbol, expresión coreada para animar a los equipos nacionales. Se trataba de una expresión elegida para suscitar, en una etapa de crisis ideológica, sentimientos de orgullo patrio. Él mismo compuso las letras del himno de Forza Italia con un estribillo pegadizo y algo pedante.

Asimismo, eligió el azul como color representativo, como la camiseta del equipo de fútbol, y los estadios y polideportivos como sedes de sus primeros actos: "para explotar estos sentimientos, Berlusconi se apropió de los lemas y símbolos del equipo. Su 'equipo' eran los 'azzurri' [azules], sobrenombre dado a los jugadores de la selección" ". El azul de la selección, el canto de los hinchas de Italia pasan a ser de propiedad de Berlusconi, que consiguió "monopolizar valores comunes y convertirlos en valores de partido": el mismo cavaliere declaraba a una radio de que debían llamarle "azzurri, no forzisti" 6 . A tal propósito, Umberto Eco advertía que "hoy en día el que grita 'Forza Italia' en un campo de deportes o habla de valores liberales y de libertad [refiriéndose al Pueblo de la Libertad, presunta evolución política de Forza Italia] se convierte inmediatamente en propagandista del Polo" 7.

Con perspicacia y conocimiento del funcionamiento de los medios de comunicación, Berlusconi puso en marcha su campaña político-mediática para convencer el país de su "no-proyecto" político. Sus televisiones, sus periódicos, sus radios, sus productoras de cine, las estrellas de sus programas televisivos orquestaban una incesante maquinaría mediática orientada a convertir a los telespectadores y los ciudadanos en votantes del partido. Y en esta primera etapa se asistió a una especie de identificación completa entre su actividad de empresario y la de aspirante político: los empleados de sus bancos y editoriales fueron nombrados organizadores del partido, los Clubs de aficionados del Milán pasaron a ser círculos del partido político Forza Italia y presentadores y vedettes fueron sus candidatos (junto con muchos ex socialistas que vieron en el partido la posibilidad de reciclarse políticamente). Durante esta campaña electoral, y todas las siguientes, los canales televisivos funcionaban como su plataforma personal, como espacio privilegiado donde hablar a los italianos "entrando directamente en sus casas".

Volviendo brevemente a la compra del Milán, merece la pena subrayar cómo, en 
un principio, pareció una operación financiera atrevida, sino incluso equivocada: el equipo estaba muy endeudado y en una difícil situación. No obstante, como decíamos, desde el punto de vista simbólico y para su proyecto a "largo plazo", la compra del Milán, junto con la propiedad de las televisiones privadas, resultó especialmente acertada: "lo que Berlusconi entendió sin duda es que el fútbol y la televisión podían fundirse para crear una sinergia explosiva"8. Berlusconi se daba cuenta de que el "fútbol había conseguido agitar emociones que tenían mucho peso político (...). [Además] Berlusconi se dio cuenta de que había dado con una fibra sensible, la fibra de la antipolítica, que iba dilatando a lo largo de los años ochenta, y advirtió también que él (símbolo de algo distinto, de una cultura completamente distinta, del mundo de la televisión, los deportes y el entretenimiento, de la iniciativa y del éxito económicos) se iba erigiendo en un poderoso pararrayos de dicho sentimiento"9.

Asimismo se debe reconocer que la decisión de Berlusconi de entrar en el mercado del fútbol, provocó un gran revuelo y cambió las reglas del juego en Italia, transformando la industria del fútbol. Empezó a comprar jugadores, ofrecer contratos estratosféricos, convulsionando el mercado de fichajes de Italia y del mundo, propiciando una guerra de ofertas que terminó con el fuerte endeudamiento de diferentes equipos. Al mismo tiempo, el futuro presidente del Gobierno inauguraba una masiva campaña publicitaria del equipo que concluyo con la venta de casi $65 \mathrm{mil}$ abonos. Asimismo, aumentó el número de aficionados del A. C. Milán, que históricamente ya contaba con un gran seguimiento a escala nacional (sobre todo en las regiones del sur Italia), un crecimiento proporcional al número de ligas ganas: en todo el país, se crearon círculos, clubs o peñas del Milán, una red capilar cercana que certificaba la presencia del magnate en el territorio nacional. La popularidad de Berlusconi aumentaba según los triunfos del Milán y el Presidente registraba auténticos baños de masas cada vez que seguía al equipo. Los aficionados del Milán le adulaban, exaltaban su figura y confiaban en sus virtudes hasta el punto que, según el mismo Berlusconi, una vez, uno le reveló: "Silvio, si quieres votamos por cualquier partido que tú no digas. Le damos ocho millones de votos al partido que quieras. ¡Aunque personalmente dártelos a ti sería lo mejor!", al que el futuro presidente del Gobierno italiano -siempre según su relato- impactado y satisfecho, confesó: "Amigo, de hecho estoy pensando en fundar mi propio partido" 10.

Con su forma de hacer, sus palabras y sus gestos había convencido a los aficionados del A.C. Milán. Berlusconi aparecía como el hombre que no sólo podía hacer todo lo que se proponía, sino también como el hombre capaz de hacerlo todo con excelentes resultados. A tal propósito Indro Montanelli afirmaba de forma clarividente y sabia: "los seguidores rossoneri están exultantes. Se muestran convencidos de que Berlusconi transformará al Milán en equipo campeón en un abrir y cerrar de ojos, y puede que tengan razón. Sólo existe un peligro: que el nuevo presidente del Milán desee también ser director general, entrenador, masajista, capitán y delantero centro. Lo cual podría no ser una mala cosa siempre y cuando consiga ser también el árbitro"11. 


\section{La subida al poder de Berlusconi}

La compra del A.C. Milán escenifica la metáfora del mundo según Berlusconi, siendo a la vez emblema de su visión empresarial y política, combinando pasión e interés. Así es, la presidencia del Milán acompañó su ascenso político, utilizando el púlpito del fútbol para hacer prosélitos y votantes. El fútbol con su poder mediático se convirtió en una plataforma desde donde lanzar mensajes o con finalidades electorales.

Los medios de comunicación, los almacenes Standa, el A.C. Milán sirvieron a Berlusconi para difundir una imagen de sí mismo en la conciencia nacional, la idea de un triunfador y hombre de éxito. Utilizando el fútbol para finalidades políticas, Berlusconi se convirtió de Presidente del Milán a Presidente de Gobierno de Italia. En diferentes ocasiones Berlusconi acudió al fútbol para mejorar su posición política o para distraer a la opinión pública ante uno de sus múltiples escándalos. Veamos algún ejemplo.

Desde que Berlusconi decidió entrar en política, el deporte marcó su lenguaje, empezando por la ya citada expresión de "saltar al campo". Como decíamos, incluso el nombre del partido político fundado por Berlusconi resultaba funcional a este diseño, un nombre-marca que el crítico literario, Alfonso Berardinelli, definió "infantile, trionfale, calcistico, volutamente osceno"12.

Como ya decíamos, no obstante, la elección del nombre del partido respondía a un preciso cálculo político: "no es en absoluto casual que bautizara a su partido como Forza Italia. Cuando las llamadas a la revolución o las invocaciones a la madre patria se debilitan, la selección nacional parece el único factor que puede avivar poderosos sentimientos nacionalistas en la mayoría de los italianos, y Berlusconi ha canalizado astutamente esos sentimientos hacia sus propios objetivos políticos"13.

Si en la segunda etapa política Berlusconi explicaba de forma mesiánica su decisión de ingresar en la política, como una especie misión providencial que cumplir ${ }^{14}$, cuando hizo su primera aparición en el escenario político consideró más rentable el recurso a la eterna lucha entre el bien y el mal, entre los buenos -los conservadoresy los malos -los comunistas. Como si se tratara del partido final de la película "evasión o victoria" (de 1981), el cavaliere exhortaba a los buenos a votar en contra de los malos, alentando el fantasma de un comunismo todopoderoso (pese a la caída del Muro de Berlín...), que tenía que ser derrotado por los defensores de los buenos valores reaccionarios. Anteriormente a su decisión de lanzarse a la arena política, resultó muy comentada su frase pronunciada cuando, con ocasión del final de la Liga de Campeones de 1989 contra el Steaua de Bucarest, el presidente del Milán afirmó que el mismo había "rezado para que pierdan los comunistas", cargando el partido de elementos ideológicos hasta entonces impensables. Presentándose como el paladín capaz de defender la democracia italiana del peligro rojo, Berlusconi recurrió a la amenaza comunista incluso en los últimos años de Gobierno, considerando siempre válida la estrategia de oponerse a un enemigo.

El 10 de mayo de 1994, Berlusconi es nombrado Presidente del Gobierno italiano por primera vez, como resultado de una excelente campaña mediático-electoral, 
centrada en su figura como modelo de éxito tanto en los negocios como en el deporte. Anteriormente a la contienda electoral, el departamento de marketing publicitario-político del cavaliere había investigado acerca de las expectativas y las promesas que los italianos deseaban obtener con el fin de centrar su campaña en esto. Ya en el verano de 1993, Berlusconi había realizado unas encuestas para sondear la posibilidad de presentarse como primer ministro, revelando que su nombre era conocido por el $97 \%$ de sus votantes potenciales, mientras el del entonces primer ministro, Carlo Azeglio Ciampi sólo por un 51\% ${ }^{15}$.

Como demostración de esto, el periodista británico, Garton Ash, tras su visita a Italia en estos mismos años, cuenta: "me dicen que Berlusconi inició su irrupción en la política italiana realizando amplios y complejos sondeos de opinión. Cuando averiguó lo que quería la gente, se lo ofreció, lo envolvió en papel brillante y lo vendió con las más modernas técnicas publicitarias en los canales de televisión de su propiedad. Es casi una parábola - ¿o parodia?-de la democracia contemporánea de la televisión". Y añade: "Me llevan a una tertulia televisiva en la que se habla de si existe alguna relación entre el éxito del equipo de fútbol del Milán, que pertenece a Berlusconi, y el reciente triunfo de éste en política. ¿La política se parece al fútbol? El presentador, que es de izquierdas, sugiere un paralelismo: el éxito de Berlusconi en el fútbol, indica, se debe a que compra jugadores..."16.

Confirmando la estrecha vinculación entre el equipo del Milán y Berlusconi, afirmaba Luigi Crespi, ex responsable de la empresa encuestadora del cavaliere, que "Nel 2001 mi venne commissionato uno studio molto approfondito dal quale emerse che il Milan e Berlusconi erano percepiti come la stessa cosa"17.

Siempre en 2011, antes del partido contra el Deportivo de la Coruña, Berlusconi volvía a meter el fútbol en la campaña electoral, animando su equipo a ganar, afirmando: "Vi parlo come futuro presidente del Consiglio. Sono sicuro che stasera vincerete, per quei 60 mila tifosi che aspettano la vostra vittoria, così come io vincerò per i 50 milioni di italiani che si aspettano la mia" 18 .

La campaña electoral de 2008 certificó la importancia del deporte y el ingreso oficial del fútbol en la puja electoral. Tras la breve y decepcionante experiencia de Gobierno de Romano Prodi, Italia se preparaba para unas nuevas elecciones el 13 y 14 de abril de 2008. Lo curioso es que esta vez no fue solo Berlusconi quien quiso utilizar el fútbol para mover votos, sino también su contrincante, Walter Veltroni. Por un lado, Berlusconi cerró su campaña electoral en Milán, anunciando como medida estrella de su futuro Gobierno el...fichaje del brasileño Ronaldinho. No se habló de lucha contra la criminalidad organizada, ni de recuperación del Mezzogiorno de Italia, sino especialmente de éxito deportivo. El cavaliere bien sabe que, en términos de votos, los electores responden a tres factores: promesas económicas, que ya había lanzado, incluso de forma irresponsable (como eliminar el impuesto sobre la primera vivienda); una masiva campaña publicitaria, también realizada a través de un agobiante bombardeo con la cara de Berlusconi, su foto aparecía en todas las calles o televisiones nacionales; $y$, en tercer lugar, un golpe de efecto, como el anuncio resonante del fichaje de Ronaldinho. Por su parte, Veltroni había llenado la capital, Roma, con una frase de apoyo del eterno capitán y símbolo de Roma -y de la roma- 
nidad-, Francesco Totti. El aspirante del Partido Democrático confiaba en la movilización del voto, apoyándose en un jugador simpático y bien valorado por los italianos. La reacción de Berlusconi no se hizo esperar, atacando Totti y acusándole de "no estar bien de la cabeza"19. En un segundo momento y ante la crítica de diferentes medios e incluso famosos políticos italianos (Andreotti definió la actitud de Berlusconi, en términos futbolísticos, como "fuera de juego"), el cavaliere pidió perdón, acusó la izquierda de instrumentalizar las palabras del futbolista y recordó, en tono amenazador burlesco, que "su esposa trabaja para mi, en mis televisiones" 20 . Berlusconi llegó a acusar su adversario político de deslealtad e inmadurez por haber recurrido al apoyo de un futbolista, recordando que numerosos jugadores de su equipo se habían ofrecido para hacerle campaña e incluso alguno había mostrado su disponibilidad para figurar en las listas de su partido. Y, para concluir su campaña de desacreditación del adversario, afirmó con aire soberbio: "Veltroni il calcio l'ha visto solo sulle figurine" 21 .

Durante la campaña electoral de 2008, en diferentes ocasiones Berlusconi se presentó a sí mismo como un Presidente ganador, repitiendo hasta la saciedad que "Yo siempre gano, estoy condenado a vencer". En varias ruedas de prensa, en lugar de presentar propuestas serias o un programa político, afirmaba simplemente: "Soy el Presidente que más títulos ha ganado y el fútbol se acordará de mí". Presentarse como el Presidente que más victorias había logrado, se convirtió casi en una obsesión y en mayo de 2011 llegó a afirmar: "soy el presidente que más ha ganado en la historia del Milán. Bernabéu, que es el segundo, no ha ganado ni la mitad de los trofeos que gané yo", adelantado su deseo de que se pusiera su nombre al estadio del Milán.

Antes de las elecciones del Parlamento europeo de 2009, Berlusconi parecía comprender perfectamente la influencia de sus actos como presidente del Milán sobre el voto de los ciudadanos de la capital de Lombardia. Por esa misma razón intentó retrasar lo más posible la noticia del fichaje de Kaka por el Real Madrid. Sabía que esto podía perjudicarle electoralmente y estuvo desmintiéndola hasta que el fichaje no se hizo oficial. Una vez oficializado, su estrategia cambió pasando de un "imposible retener a Kaka" a una frase que podría resultar incomprensible si no fuera totalmente cierta: "La culpa de estos resultados es de mi esposa [ex, Veronica Lario], de Kaka y de Noemi [escándalo de la chica de 18 años]"22. Para el entonces presidente del Gobierno, su partido perdió un $10 \%$ de votos respecto a lo esperado no por su mala gestión o por los escándalos judiciales, sino más bien por sus asuntos personales y privados y la cesión del astro brasileño. Kaka ha sido un tema recurrente en la carrera política del Berlusconi, tanto que en sus horas más bajas como presidente del Gobierno, volvió a mencionar su posible fichaje ${ }^{23}$, apelando al buen recuerdo que el futbolista carioca ha dejado en Italia, tanto como jugador cuanto como profesional y persona seria.

Momento emblemático de la importancia que iba teniendo el fútbol para el entonces presidente del Gobierno fue el verano de 2010, cuando, tras un periodo de "desamor futbolístico", Berlusconi fichó en menos de 48 horas (30-31 de agosto) a Ibrahimović y Robinho, pagándoles más de 40 millones de euros. Sobre esta sorpren- 
dente operación hay dos diferentes explicaciones: por un lado, algunos comentaristas deportivos italianos la describieron como una "reacción" a las decepciones políticas del momento, como manera para "recobrar" animo ante el desengaño de algunos aliados. Por otro lado, para muchos periodistas y personajes cercanos a Berlusconi, tras los fichajes había mucho más. Según lo que revelaba el ya citado Crespi, una importante personalidad (Carmelo Messina), cercana al entonces presidente del Gobierno, le encargó un sondeo cuyo resultado no dejaba de sorprender: debido a la desafección del último momento y a los malos resultados de los últimos años (como el Triplete de los eternos rivales del Inter), "il premier avrebbe rischiato di perdere il 20-25 per cento dei milanisti che votano Pdl. In termini elettorali si sarebbe trattato di una perdita di almeno mezzo milione di voti, vale a dire di 2 punti percentuali" 24 .

Aunque suene paradójico, la dedicación e inversiones del presidente del Milán parecían directamente proporcionales al consenso político y electoral que se daba al presidente del Gobierno. Por eso, decidió comprar las dos estrellas futbolistas internacionales, generando la ironía de los mismos aficionados milanistas que, en diferentes foros, auguraban elecciones en enero soñando con poder fichar así también a Cristiano Ronaldo. En un clima de estabilidad y con una mayoría gubernamental debilitada, según muchos, los fichajes eran la señal de que el Presidente del A.C. Milán entraba en campaña electoral. Asimismo se cuenta que Berlusconi temía más -y tomaba más en serio- la contestación de los aficionados en el día de presentación del equipo o en la pretemporada que cualquier crítica de la oposición.

A la luz de todo esto, resulta evidente que los fichajes se han convertido en un "arma mediática", un escaparate y un instrumento útil en clave electoral.

Sucesivamente, ante el avance electoral de centro-izquierda, en los últimos meses de su Gobierno, Berlusconi volvió a relucir el tema futbolístico, llegando incluso a compararse con Ibrahimović: "Pensate se a guidare l'Italia ci fossero Bersani, Di Pietro e Vendola. Una squadra che non ha un fuoriclasse. Vedete invece il Milan che con Ibrahimovic vince la partita. Io sono un fuoriclasse che ha salvato l'Italia dal default preparato da Romano Prodi quando ha permesso il cambio liraeuro" 25 .

\section{La transformación de la política y del lenguaje}

En esta nueva etapa política, se ha asistido a una progresiva transformación de la política en un campo de fútbol, el Parlamento convertido en un estadio, donde llevar pancartas contra el adversario, pitar, insultar e incluso intentar enfrentarse físicamente al contrario, dando desahogo a los peores instintos humanos. En estos años, se han sucedido episodios lamentables dentro del Parlamento italiano, debates convertidos en riñas: esputos e insultos en enero de 2008, gritos y abucheos en marzo de $2011^{26}$, golpes y manotazos en 26 de octubre de $2011^{27}$, etc. Hemos vistos diputados asistir a sesiones parlamentarias con camisetas con mensajes políticos, mofándose de su adversario.

Asimismo, en los últimos años, faltaba seriedad y objetividad en los discursos y 
debates en torno a los problemas de Italia, de natura económica, política o institucional. Las discusiones se parecían cada vez más a las que se entablaban en los Bar dello Sport, asistiéndose a una bipolarización de los participantes, divididos en bandos, con ciegas convicciones en su partido como un hincha por su equipo. En lugar de presentar propuestas constructivas o críticas productivas, se limitaban a descreditar al adversario, insultar como si se estuviera en un partido de fútbol.

En este escenario, los ciudadanos se han convertido ellos mismos en hinchas, encargados de vitorear y defender a su partido, a sus colores: se trata de una defensa incondicional, independiente de si se aprueba o no su gestión política, animada por el "amor" a su propio bando y "odio" al bando opuesto. Los italianos desde siempre proclives a debatir de política fueron sustituyéndola gradualmente por el deporte, que se convirtió en el principal tema de conversación de los ciudadanos. Parecía que en una etapa de crisis ideológica -el fin de la Guerra Fría y el derrumbe del bloque Soviético- y de desconfianza hacia los políticos -el escándalo de Manos Limpias-, las discusiones deportivas reemplazaban la política y en todas partes se comentaban alineaciones, elecciones tácticas, decisiones arbitrales...

Los mismos debates de la televisión, las tribunas políticas y las entrevistas asumen las características de un encuentro de fútbol: se silba al adversario, se insulta al presentador-arbitro, siempre se declara la propia victoria. Es evidente que Berlusconi no es el único responsable de este cambio de canon, pero sí uno de los culpables y uno de los que más ha contribuido al deterioro de la política italiana, introduciendo un nuevo modelo, un nuevo modo de interpretar la política, más cercano al mundo del deporte que a la contraposición ideológica.

No obstante, merece la pena subrayar que el uso del deporte como técnica de comunicación política por parte Berlusconi no fue del todo novedoso y, más bien, siguió el camino ya emprendido por otros, mejorándolo y adaptándolo a una Italia en constante transformación. Entre tantos posibles antecedentes, basta con citar dos celebres casos: por un lado, Achille Lauro, empresario, Presidente del equipo de fútbol de Nápoles y alcalde de la ciudad desde 1952 al 1957, conocido por sus legendarias capacidades amatorias y su populismo, que encontraba perfecta escenificación en la cierta anécdota de regalar, en los barrios más pobres y marginados de la ciudad, pasta y un par de zapatos: el izquierdo se entregaba antes de la contienda electoral y el derecho tras la victoria. Como Berlusconi fue cavaliere del lavoro y, durante su larga presidencia del Nápoles, caracterizada por varios golpes de efecto, fichajes estrellares (como Luis Vinicio, Bruno Pesaola el "Petisso", y, sobre todo, Hasse Jeppson, estrella sueca, pagada, en 1952, 105 millones, resultando el fichaje más caro de entonces) y promesas de grandeza, utilizó el futbol como enorme caja de resonancia, instrumento para difundir su nombre entre la gente y ser elegido alcalde con casi 300.000 votos, límite jamás alcanzado anteriormente por un candidato en las elecciones locales. Asimismo, en las elecciones generales de 1953 consiguió 680.000 votos para la Cámara de Representantes, cifra jamás alcanzada por diputado alguno hasta entonces ${ }^{28}$. Por otro, el mentor político de Berlusconi, Bettino Craxi, que promovió la llamada "via pallonara al socialismo" 29 , promoviendo la elección como diputado de Gianmauro Bersano, entonces presidente del Torino, el equipo favorito 
del secretario del PSI (Partido Socialista italiano), cuya etapa política resultó especialmente breve ya que pronto fue investigado por fraude.

En los últimos años, en Italia, en España y en el Mundo en general, el fútbol se ha convertido en algo más que un deporte y su importancia traspasa el clásico panem et circenses. El fútbol se ha convertido en una ideología, en algo en que creer. Pero al mismo tiempo, representa una forma de evasión social, la posibilidad de soñar y olvidar. Los jugadores se convierten en héroes mientras el público celebra sus gestas. El deporte representa una mezcla de pasión y ardor, de religión e ilógica. Los mismos medios de comunicación se han dado cuenta de este nuevo y creciente protagonismo: cada vez dedican más espacio, tiempo e interés a temas deportivos. Paradójicamente, saben que tener un enviado en el Santiago Bernabéu o en el Camp Nou resulta casi tan importante como tener un corresponsal en Washington o en Moscú. En términos de espectadores, audiencias o lectores, es muy probable que el partido de tenis entre Nadal Vs. Federer registra una mejor audiencia que el debate entre los candidatos a la presidencia de Estados Unidos. La actividad deportiva marca la agenda de los medios, fijan los temas a debatir, marginado -o incluso silenciando- a la minoría contraria, generando una especie de espiral del silencio en torno al deporte.

En el caso de Italia, se ha asistido a un progresivo aumento de programas y tertulias dedicadas al deporte, del número de partidos televisados, del espacio concedido al tema por parte de periódicos (sobre todo en su edición del lunes), radios y televisiones: "Antaño, la RAI sólo televisaba la media de un partido por semana, y lo hacía cuando éste había finalizado, convencida de que nadie acudiría a los estadios si los partidos se trasmitían en directo. Berlusconi acabó con esas convicciones y pasó a emitir varios partidos a la semana, así como numerosos magazines en los que, a partir del domingo por la noche y durante varios días, entrenadores de salón debatían las competiciones del fin de semana" 30 . Creció exponencialmente el número de programas de debates deportivos, de magazines, de espacios dedicados al fútbol. Y, el mismo periodista internacional, Alexander Stille, subrayaba como "en tanto que la propiedad de un equipo pueda no ser lucrativa, el fútbol televisado lo es indudablemente, y su propio arraigo popular es tal que las retrasmisiones futbolísticas pasaron a convertirse en una auténtica fuerza cultural" 31 .

Volviendo al binomio deporte-poder, el uso político del deporte no resulta un fenómeno novedoso y su poder comunicativo era bien conocido ya en la época de los emperadores romanos, que utilizaron circos y gladiadores fundamentalmente como arma de propaganda. Hoy en día, los diferentes políticos, consideran el deporte de gran utilidad, una forma de evasión que puede ayudar a que los ciudadanos no centren su atención sobre los acontecimientos de actualidad, distraídos por actualidad deportiva. En este sentido, los medios de comunicación, a servicio del deporte, contribuyen a tergiversar o, en casos extremos, ocultar la realidad, fomentando el olvido y la distracción, la diversión y el espectáculo.

Asimismo, el fútbol y los demás deportes no representan sólo una forma para entretener al pueblo, a las masas, sino también una herramienta para controlarlo. No pocos regímenes dictatoriales han utilizado el deporte para sus fines, afianzar su autoridad u obviar su imagen: el mismo Mussolini se dio cuenta del potencial polí- 
tico del fútbol y durante su régimen hizo construir alrededor de 3.000 campos de fútbol, convirtiéndolo en el deporte nacional. Asimismo, la Italia de Mussolini utilizó las victorias en los Mundiales de fútbol de 1934 y 1938 como ocasión para dar propaganda a la ideología fascista, avivar el sentimiento nacional patriótico y demostrar una presunta superioridad de los fascistas italianos.

En la dialéctica de Berlusconi, el tema del fútbol, el deporte por antonomasia para los italianos, resulta recurrente, representando algo más que el habitual recurso propagandístico de los regímenes totalitarios: "L'acquisto del Milan nel 1986, trasformata nel giro di due anni da squadra perdente in vincente a livello nazionale (nel 1988 arriva il primo scudetto), e poi internazionale, non va interpretato come un ulteriore episodio dell'uso propagandistico dello sport, tipico dei regimi totalitari, ma come l'istituzione di un regime del sogno: far sognare i tifosi, e non solo loro"32.

El fútbol, convertido en la pantalla sobre la cual proyectar la psique italiana, servía para dar a los ciudadanos la posibilidad de soñar, abstraerse de la realidad, entretenerse y tener rivales. Por eso, en una ocasión, en apuros ante unas preguntas incómodas, ilógicamente, Silvio recurrió al fútbol, defendiendo sus habilidades y virtudes: "Pruebe a ganar uno Scudetto antes de tratar de desafiarme".

En la misma línea, tras la decepcionante derrota contra el modesto Cesena en el debut de Ibrahimović y Robinho, Berlusconi excusó su equipo y declaró: "il problema è che spesso il Milan si imbatte in arbitri di sinistra"33. El periodista Severgnini invita a un ejercicio dialectico, a sustituir "Milán" con "partido" y "árbitros" con "Magistrados" para descubrir que no se trata de una opinión novedosa ${ }^{34}$, sino más bien de un recurso típico de la retorica berlusconiana, los ataques a la togados rojos: en diferentes ocasiones, Berlusconi ha puesto en marcha su maquinaria de descalificación contra la Justicia italiana, acusándola de inventar procesos, de perseguirle políticamente y judicialmente, de entorpecer su acción política (y la vida cotidiana de los italianos) e incluso de no creer en su buena fe cuando, en el caso de corrupción judicial juró por la cabeza sus hijos su inocencia.

Capítulo aparte merece el recurso a las metáforas futbolísticas o las referencias directas a los fichajes. Berlusconi considera el fútbol y el deporte como un instrumentum regni, un instrumento útil para construir el consenso y convertir los tifosi en la base social de un partido político. Por eso, como afirma un sociólogo italiano, a partir de 1994, con la decisión de Berlusconi de entrar en la arena política, empieza "la nuova fase, che coincide con l'interesse diretto di Berlusconi in politica, può essere definita dal doppio processo di politicizzazione del calcio e calcistizzazione della politica"35. A partir de este momento, de forma más clara que en el pasado, se ha asistido a un doble proceso de "politicización del fútbol y de futbolización de la política". Consecuencia de esta miscelánea entre los dos temas, será la hibridación del lenguaje tanto político como deportivo, utilizando palabras e imágenes capaces de despertar pasiones en los electores o en los espectadores, estimular la imaginación del público en clave electoral.

Por eso mismo, no debe extrañar que, en el cierre de la campaña electoral para las administrativas de Nápoles, en una Plaza Plebiscito, llena de aficionados y votantes, Berlusconi prometiera que, en caso de victoria de su candidato a la alcaldía 
de la ciudad, no ficharía a la joven estrella del Nápoles, Marek Hamsik ${ }^{36}$. Evidentemente, se trataba de una promesa futbolera de escasísimo valor político pero de gran valor deportivo, sobre todo teniendo en cuenta el fervor y la exaltación con la que se vive el deporte en la ciudad eternamente enamorada de Maradona.

El Presidente del A.C. Milán ha comprendido el poder de los medios de comunicación de masas, su capacidad de penetración en la esfera domestica de los ciudadanos, la necesidad de satisfacer los gustos de los espectadores. Deporte y Televisión como armas estratégicas: Berlusconi, "a diferencia de sus adversarios, ha comprendido que el destino político se determina en otra parte. Por ejemplo, en televisión. Más precisamente: televisión en prime-time, de las 19 a las 21 (...). Minimizan la corrupción, esconden la turbación, ocultan problemas e intrigas (...). La televisión, en una democracia, cuenta" ${ }^{37}$. El actual presidente del Consejo bien sabe que, mientras los periódicos los leen una minoría, la televisión la ven todos y ha comprendido que el consenso se controla controlando los medios de información más difundidos. Mientras Mussolini consideraba que el cine era el arma más poderosa -"Si Mussolini hubiese tenido televisiones, estaría todavía aquí,, aseguraba Montanelli-, actualmente el arma más fuerte es la televisión y, por esa razón, a lo largo de sus mandatos y en presencia de un evidente conflicto de intereses, al primer ministro le ha interesado preservar su control, representando por el más persuasivo de los medios de comunicación social. Asimismo, entre las máximas preferidas de Berlusconi, se suele citar la siguiente, que el ex mandatario italiano repite hasta la saciedad: "si no sale en televisión, es que no existe".

Merece la pena recordar, que, en el lejano 1974, el escritor Primo Levi escribía sabiamente que "cada época tiene su fascismo" advirtiendo, con extrema clarividencia, que "se puede llegar a esta situación de muchas formas, no necesariamente mediante el terror y la intimidación policial, sino también a través de la ocultación o de la manipulación de la información, la corrupción del sistema judicial y la parálisis del sistema educativo"38. Por su parte, Umberto Eco afirmaba que cada época tiene sus mitos y que, hoy en día, el mito del Hombre de Estado (al estilo de Mussolini) ha sido sustituido por el Hombre de Televisión: por lo tanto, "en nuestro época, si tiene que haber una dictadura, ha de ser una dictadura mediática y no política"39.

\section{El fenómeno Berlusconi}

Berlusconi ha demostrado como, dentro de un sistema democrático, puede obtenerse el control político, utilizando el poder de los medios de comunicación y una ingente fortuna económica. A través de la posesión de diferentes medios de comunicación (prensa, radio, TV, cine, editoriales...), el presidente del Milán Futbol Club pudo alcanzar el poder, dando vida a la insólita situación de un gran patrono de medios de comunicación que logra controlar el poder político directamente, provocando una peligrosa confusión entre intereses públicos y privados, personales y gubernamentales.

Berlusconi es el prototipo del líder mediático y de eso depende su éxito: “el líder 
mediático es capaz de interpretar antes que nadie las reacciones del hombre de la calle y las representa con gestos que los medios pueden reproducir con facilidad y rapidez. Vigila en tiempo real los humores de la opinión, responde a sus reacciones y la interpela de forma directa. En esto, hay una parte de intuición e improvisación y una parte de cálculo. El líder mediático establece una conexión mágica entre la normalidad del país y las vicisitudes públicas y privadas del líder político. Cultiva y explota esta identificación y los medios la reflejan y la amplifican. Una simbiosis ficticia, dirán algunos, pero real como la vida misma" 40 .

Desde el punto de vista dialectico, durante estos años, la agresividad verbal ha entrado de lleno en la comunicación política cotidiana: se acusaba al enemigo con palabras fuertes, vacías de contenido. Al mismo tiempo, el ex primer Ministro utilizaba un repertorio argumentativo recurrente, monotemático: el sacrificio, la inocencia victimista, la conjura, el conflicto entre bien y mal, su intervención divina, la innata difidencia, recelo y desconfianza del pueblo italiano hacia la magistratura, el modelo de éxito a imitar. Y por otro lado, en su intento de crear "empatía" con sus electores, se mostraba comprensivo, como si fuera uno de ellos, con los mismos vicios y virtudes, buscando la captatio benevolentiae de los espectadores de sus televisiones. El cavaliere se mostraba dispuesto a admitir sus tentaciones terrenas y debilidades humanas, "a perdonar las de los otros" siempre en un régimen de reciprocidad, proponiendo un intercambio de tolerancia y justificación mutua. Como ya decíamos cuando se hablaba del efecto Zelig, desde el punto de vista sociológico Berlusconi se adapta al ambiente que le rodea, mostrándose capaz de construir una empatía con sus electores, hacerles creer que, pese a que lleva 20 años en la política italiana, sigue representando la novedad, el aclamado homo novus y, sobre todo, que todos ellos pueden ser como él. Todos pueden ser dueños de un equipo de fútbol o grandes amadores.

Tal y como decíamos al principio del artículo, resulta interesante y útil comprender la estrategia que Berlusconi ha utilizado para alcanzar el poder ya que su estilo y su destreza podrían ser exportados, como ya demuestran el caso de Tailandia o Chile: "el modelo impuesto por el cavaliere, caracterizado por la políticaespectáculo, el estilo personalista y 'seudo-plebiscitario' es exportable y podría aspirar a ser emulado por varios gobernantes" 41 . Se trataría de un modelo revisado y adaptado a las características locales, teniendo en cuenta los hábitos y las costumbres del país en el que se implemente. El estilo del primer ministro italiano, la mezcla de populismo y demagogia, el uso del deporte en clave política podrían peligrosamente convertirse en un paradigma para otros mandatarios. Por eso, resulta crucial comprender y valorar en qué medida, qué posibilidad puede darse de que modelo italiano se extienda en un futuro hacia otros países del mundo. El modelo de Berlusconi, con su violación de las reglas fundamentales de la democracia, podría propagarse por otros países, superar las fronteras: frecuentemente Italia ha estado a la vanguardia de las tendencias socio-políticas que luego se han implantado en el Mundo (léase fascismo por ejemplo) y por eso, el modelo populista-conservador podría trascender e irradiarse en el continente. "Esperemos que Italia, con el fenómeno Berlusconi, no esté una vez más negativamente a la vanguardia", como afirmó 
el escritor italiano Claudio Magris en una entrevista.

Un régimen -sultanado, una dictadura mediática, una dictablanda, un totalitarismo soft o un cesarismo guiado por un pequeño césar- que poco se ha preocupado de respetar los principios fundamentales de un Estado democrático, atentando constantemente contra el Estado de Derecho y promulgando la mayoría de las leyes en forma de decretos, para evitar así el debate parlamentario. Aunque paradójico, Berlusconi consiguió ser elegido y actuar como el controlador que todo controla, creando un mercado de colusión entre política y negocios; convirtiendo sus intereses privados en asuntos públicos, de Estado y como tales se preocupó de tutelarlos; y, finalmente, aún más grave, en lugar de ser pluralistas, los medios que deberían contribuir a la formación de la opinión pública pertenecían a una única persona, que, a través de su monopolio, ha promovido un discutible modelo socio-político, cambiando los modelos sociales imperantes en la sociedad y sustituiodos por un nuevos, más vulgares.

Aún, así, fuera de Italia, no siempre ha resultado fácil comprender el fenómeno Berlusconi, provocando su figura curiosidad y generando alguna incomprensión. En las últimas décadas, la opinión pública internacional se ha frecuentemente preguntado cómo fue posible que los italianos no sólo le perdonasen todo, sino que incluso le votaran mayoritariamente. Dentro de Italia, la figura de Berlusconi puede entenderse -quizás no comprender del todo- ya que no representa "un extraterrestre", una figura ajena al país, sino más bien el producto de la actual sociedad italiana. Por eso, El País le presentaba como "un ejemplar italianísimo, un producto puramente made in Italy: simpático, campechano, elegante, ocurrente. Sólo un país tan fascinante, contradictorio y cínico como Italia puede inventar un político as'" 42 . No cabe duda que el cavaliere ha encarnado perfectamente la italianidad actual, convirtiéndose en el perfecto intérprete de la sociedad civil y de sus deseos. Describiendo la personalidad de Mussolini, Curzio Malaparte sostenía que "no se puede realizar un retrato de Mussolini sin hacer un retrato del pueblo italiano. Sus cualidades y defectos son las de todos los italianos". De igual manera, no podría entenderse a Berlusconi si se le extrapolara de su contexto, apartándole de la sociedad italiana de los últimos años. Como si todos los italianos llevásemos dentro algo de Berlusconi, tanto que el genial Giorgio Gaber afirmaba, en 2001, con clarividencia: "no tengo miedo de Berlusconi en sí, tengo miedo de Berlusconi en mí".

\section{Conclusiones}

El deporte representa un fenómeno de masas en el que intervienen numerosos actores e interesa a campos como la sociología, la política, la economía y los medios. Berlusconi entendió que, en Italia, el fútbol representaba un ámbito estratégico que tenía que dominar como trampolín hacia su carrera política. Tal y como se ha expuesto en estas páginas, desde el principio de su aventura, consideró el fútbol como un medio para llegar a la gente y la compra del A.C. Milán como un escaparate, un instrumento para darse a conocer. 
Por lo tanto, no se puede entender la figura de Berlusconi y su subida al poder sin tener en cuenta su faceta de presidente del Milán. En estas dos décadas, el deporte no solo no se ha quedado al margen de las elecciones italianas, sino que más bien ha tenido el papel protagonista. Los grandes nombres deportivos, cercanos al cavaliere, han servido para atraer la atención de los electores, distraerlos de los escándalos y convencerle para votar al "Presidente vincente".

Asimismo, la "prepotente" entrada del mundo del deporte en la vida pública italiana, ha supuesto un cambio en el lenguaje, la proliferación de términos y metáforas próximas al mundo deportivo. Se ha publicitado, por parte de Berlusconi, su Gobierno y la misma oposición, un lenguaje más directo, simplista y presuntamente más atractivo para los electores.

Finalmente, terminado el régimen de Berlusconi, aunque queda patente la necesidad de desberlusconizar a Italia, permanecerá su herencia y el recuerdo de una discutible gestión política. Y, sobre todo, quedan los cambios sociales y económicos que han supuesto estos años. Mientras tanto, el cavaliere seguirá siendo el Presidente del A.C. Milán, con sus manías de protagonismo y su megalomanía, soñando parecerse a Napoleón con una única diferencia, según el mismo Berlusconi, que afirma "definitivamente yo soy más alto".

El uso político y electoral del deporte nunca ha sido tan masivo como durante los años de Berlusconi. De la importancia que el fútbol revista para los italianos se había dado cuenta incluso el mismo Winston Churchill que, mostrando un profundo conocimiento del pueblo italiano y una fina sabiduría, afirmó: "Los italianos pierden las guerras como si fueran partidos de fútbol y los partidos de fútbol como si fuesen guerras". A través del fútbol y los medios de comunicación, Berlusconi ganó el poder político del país.

\section{Bibliografía}

BELPOLITI, M. (2009). Il corpo del capo. Parma: Le Fenici.

BERARDINELLI, A. (1994). "Il paese dei balocchi conquistato dalla televisione", en Micromega, 2/94

BOBBIO, N. (2008). Contro i nuovi dispotismi. Bari: Dedalo.

CILIBERTO, M. (2011). La democrazia dispotica. Roma-Bari: Sagittari Laterza.

DAL LAGO, A. (1994). Il voto e il circo, en Micromega 1/94.

D’ANNA, S. E.; MONCALVO, G. (1994). Berlusconi in concert, Londres: Otzium, 1994

ECO, U. (2010). A paso de cangrejo. Barcelona: Debols!llo.

GARTON ASH, T. (2012). Historia del presente. Fábula Tusquets, Barcelona.

GENOVESE, R. (2011). Che cos'è il berlusconismo. La democrazia deformata e il caso italiano. Roma: Manifesto libri.

GINSBORG P. (2003). Berlusconi. Ambizioni patrimoniali in una democrazia mediatica. Turín: Einaudi.

(2006). Silvio Berlusconi: televisión, poder y patrimonio. Madrid: Foca Ediciones y 
Distribuciones.

GINSBORG, P.; ASQUER, E. (2011). Berlusconismo, Analisis di un sistema di potere. Bari: Editori Laterza.

LEVI, P. (1997). Opere, vol. I. Turín: Einaudi.

MALAPARTE, C. (1960), Tecnica del golpe de Estado. Barcelona: Plaza \& Janes.

PAGANI, P. (2003). Forza Italia: come è nato il movimento che in 5 mesi ha cambiato la politica italiana. Novara: Baroli

PELLIZZETTI, P. (2009). Fenomenologia di Berlusconi. Roma: Manifesto libri.

SARTORI, G. (2009). Il Sultanato. Bari: Laterza Editori.

SEVERGNINI, B. (2010). La pancia degli italiani. Berlusconi spiegato ai posteri. Milán: Rizzoli.

STILlE, A. (2010). El saqueo de Roma. Barcelona: Papel de liar.

\section{Notas}

1 "El fútbol es metáfora de vida: a través de los éxitos del Milán, la gente ha entendido que la mía es una filosofía ganadora, que trabajando se puede alcanzar resultados ambiciosos". MIRTILLO, F. (2011). Sic transit gloria mundi. Roma: Aliberti editore, p.29.

2 "Los implicados en el escándalo del fútbol italiano esperan las peticiones del fiscal", en El País de1 de agosto de 1986, http://elpais.com/diario/1986 /08/01/deportes/523231206_850215.html

3 Según Gustavo Zagrebelsky, Berlusconi utilizó la expresión “bajar”, “descender” a la política para indicar una especie de visión providencial del gesto, casi a indicar "la sempiterna figura della missione redentrice che un 'salvatore' asume su di sé, lasciando la vita beata in cui stava prima lassù, scendendo a sacrificarsi per gli infelici che stanno quaggiù" (la sempiterna figura de la misión redentora que un 'salvador' asume sobre sí mismo, dejando la vida beata en la que estaba antes arriba, descendiendo a sacrificarse por los infelices que viven abajo". "La neolingua dell'età berlusconiana" de ZAGREBELSKY G. en el libro de GINSBORG, P.; ASQUER, E. (2011). Berlusconismo, Analisis di un sistema di potere. Bari: Editori Laterza, p. 224.

4 'Manca finezza' de BASTENIER M. Á., en El País, de 16 de noviembre de 2011, http://www.elpais.com/articulo/internacional/Manca/finezza/elpepiint/20111116elpe piint_11/Tes

5 Stille, A. (2010). El saqueo de Roma. Barcelona: Papel de liar, p. 25.

6 “Chiamateci azzurri, no forzisti”, Radio Anch'io, 7 de mayo de 2003.

7 Eco, 142.

8 STILlE, A. (2010). El saqueo de Roma. Barcelona: Papel de liar, p. 143.

9 Ibidem, p. 145. 
10 D’ANNA, S. E.; MONCALVO, G. (1994). Berlusconi in concert, Londres: Otzium, 1994, p. 146.

11 D’ANNA, S. E.; MONCALVO, G. (1994). Berlusconi in concert, Londres: Otzium, 1994, p. 138.

12 "Infantil, triunfal, futbolístico, conscientemente obsceno". BERARDINELLI, A. (1994). "Il paese dei balocchi conquistato dalla televisione", en Micromega, 2/94

13 STILlE, A. (2010). El saqueo de Roma. Barcelona: Papel de liar, p. 31.

14 El célebre Don Verzé definió a Berlusconi, en repetidas ocasiones, como un "dono de Dios" (véase CAZZULLO, A. Il Cavaliere? Un dono di Dio all'Italia, Corriere della Sera, 6 novembre 2009 ). A tal propósito, Beppe Severgnini se preguntana sarcasticamente cual era su objetivo, si ayudarnos o ponernos a prueba. SEVERGNINI, B. (2010). La pancia degli italiani. Berlusconi spiegato ai posteri. Milán: Rizzoli, p. 43.

15 PAGANI, P. (2003). Forza Italia: come è nato il movimento che in 5 mesi ha cambiato la politica italiana. Novara: Baroli, p. 33.

16 GARTON ASH, T. (2012). Historia del presente. Fábula Tusquets, Barcelona, 153154.

17 "En 2001 me encargaron un estudio muy profundo del que resultó que el Milán y Berlusconi eran percibidos como si fueran la misma cosa”.

18 "Os hablo como futuro Presidente del Consejo. Y estoy seguro que esta noche vosotros ganaréis para estos 60.000 aficionados que esperan vuestra victoria, así como yo ganaré para los 50 millones de italianos que esperan la mia". RIZZO, S.; STELLA, G. (2011). Così parlò il Cavaliere. Milano: Rizzoli, p. 99.

19 "La política enfrenta a Berlusconi y Totti", en Marca del 11 de abril de 2008. http://archivo.marca.com/edicion/marca/futbol/internacional/es/desarrollo/1111071.h tml

20 "Silvo Berlusconi: Only 'retards' would vote for Italy's Left", en The Telegraph del 11 de abril de 2008. http://www.telegraph.co.uk/news/worldnews/1584744/SilvoBerlusconi-Only-retards-would-vote-for-Italys-Left.html

21 "Veltroni ha visto el fútbol sólo en los cromos", Corriere della Sera, 5 de julio de 2000

22 De la noticia se hicieron eco los diferentes medios españoles: http:/www.elmundo.es/elmundo/2009/06/09/internacional/1244534886.html y también en http://internacional.elpais.com/internacional/2009/06/09/actualidad /1244498407_850215.html

23 "Berlusconi sueña con Kaká", en La Razón, del 8 de marzo de 2011, http://www.larazon.es/noticia/1195-berlusconi-suena-con-kaka

24 "El premier corría el riesgo de perder el 20-25\% de los milanistas que votan por el Pueblo de la Libertad. En términos electorales, se hubiera tratado de una pérdida de al menos medio millón de votos, es decir unos 2 puntos porcentuales". "Troppi 
sondaggi negativi e il Milan ha invertito la rotta" de COSTA, A. en el Corriere della Sera del 2 de septiembre de 2010. En el artículo se sostiene que Berlusconi, una vez más, el más rápido de todos, no permitió que el sondeo fuera ni siquiera publicado.

25 "Imaginad que a guiar Italia estuvieran Bersani, Di Pietro y Vendola. Un equipo sin estrella. A contrario, miren al Milán que con Ibrahimovic gana los partidos. Yo soy la estrella que ha salvado Italia del default preparado por Romano Prodi cuando permitió el cambio lira-euro". RIZZO, S.; STELLA, G. (2011). Così parlò il Cavaliere. Milano: Rizzoli, p. 74.

26 "Bronca en el Parlamento italiano", en El Mundo, de 31 de marzo de 2011, http://www.elmundo.es/elmundo/2011/03/31/internacional/1301579520.html

27 "A golpes en el parlamento italiano por las reformas económicas", en el $A B C$ del 26 de octubre de 2011, http:/www.abc.es/20111026/internacional/abci-bofetadas-parlamento-italiano-201110261657.html

28 Sobre una posible comparativa entre Berlusconi y Achille Lauro se recomienda la lectura del capítulo "La Napoli di Lauro: ritorno al futuro" de GENOVESE, R. (2011). Che cos'è il berlusconismo. La democrazia deformata e il caso italiano. Roma: Manifesto libri.

29 PELliZZETTI, P. (2009). Fenomenologia di Berlusconi. Roma: Manifesto libri, p. 75.

30 STILLE, A. (2010). El saqueo de Roma. Barcelona: Papel de liar, p. 31

31 STILlE, A. (2010). El saqueo de Roma. Barcelona: Papel de liar, 143.

32 “La compra del Milán en 1986, convertido en apenas dos años de equipo perdedor a vencedor a nivel nacional (en 1988 gana la primera Liga) y luego internacional, no debe interpretarse como un ulterior episodio del uso propagandístico del deporte, típico de los regímenes totalitarios, sino como la institución de un régimen de sueño: hacer soñar a los aficionados, y no solo a ellos”. BELPOLITI, M. (2009). Il corpo del capo. Parma: Le Fenici, p. 47.

33 "El problema es que frecuentemente al Milán le tocan árbitros de izquierdas", Declaración del ex primer ministro italiano en el Festival de la Juventud del 'Pueblo de la Libertad' (PDL), presente en diferentes páginas webs, entre ellas en Youtube.

34 SEVERGNINI, B. (2010). La pancia degli italiani. Berlusconi spiegato ai posteri. Milán: Rizzoli, p. 81.

35 "La nueva fase, que coincide con el interés directo de Berlusconi en la política, puede ser definida como un doble proceso de politización del fútbol y futbolización de la política", DAL LAGO, A. (1994). Il voto e il circo, en Micromega, 1/94.

36 “Dai condoni all'aspirasmog. Promesse e svarioni al voto", de 28 de maggio de 2011. http://www.corriere.it/politica/speciali/2011/elezioni-amministrativeballottaggi/notizie/28-Dai-condoni-all-aspirasmog-Promesse-e-svarioni-al-voto_2bc 11166-88f4-11e0-9363-be870bec5f6b.shtml 
37 SEVERGNINI, B. (2010). La pancia degli italiani. Berlusconi spiegato ai posteri. Milán: Rizzoli, p. 63, 65.

38 LEVI, P. (1997). Opere, vol. I. Turín: Einaudi, p. 1187

39 ECO, U. (2010). A paso de cangrejo. Barcelona: Debols!llo, p. 161.

40 "El liderazgo mediático de Berlusconi”, de GREPPI, L. en La verdad del 08 de mayo de 2009, http:/www.laverdad.es/albacete/prensa/20090508/opinion/liderazgo-mediatico-berlusconi-20090508.html

41 "Italia, Noemigate y las Europeas", de DONOFRIO, A., del 7 de junio de 2009, http://www.elimparcial.es/mundo/italia-noemigate-y-las-europeas-41232.html

42 "Berlusconi, otra vez", de MORA, M. del 20 de abril de 2008, http://www.elpais.com/articulo/reportajes/Berlusconi/vez/elpepusocdmg/20080420el pdmgrep_1/Tes

\section{El autor}

Andrea Donofrio es Doctor en Ciencias de la Información por la Universidad Complutense de Madrid, licenciado en Ciencias Políticas por la Universidad Federico II de Nápoles y Máster en Relaciones Internacionales de la SIOI de Roma. Actualmente es investigador del Instituto Universitario Ortega y Gasset. Experto en política italiana, es también columnista del periódico digital ElImparcial.es. 